\title{
Ice supersaturation in the ECMWF integrated forecast system
}

\author{
A. M. Tompkins, ${ }^{\mathrm{a} *}$ K. Gierens ${ }^{\mathrm{b}}$ and G. Rädel ${ }^{\mathrm{c}}$ \\ a European Centre for Medium-Range Weather Forecasts, Reading, UK \\ b Institut für Physik der Atmosphäre, DLR Oberpfaffenhofen, Germany \\ c Department of Meteorology, University of Reading, UK
}

\begin{abstract}
A parametrization for ice supersaturation is introduced into the ECMWF Integrated Forecast System (IFS), compatible with the cloud scheme that allows partial cloud coverage. It is based on the simple, but often justifiable, diagnostic assumption that the ice nucleation and subsequent depositional growth time-scales are short compared to the model time step, thus supersaturation is only permitted in the clear-sky portion of the grid cell.

Results from model integrations using the new scheme are presented, which is demonstrated to increase uppertropospheric humidity, decrease high-level cloud cover and, to a much lesser extent, cloud ice amounts, all as expected from simple arguments. Evaluation of the relative distribution of supersaturated humidity amounts shows good agreement with the observed climatology derived from in situ aircraft observations. With the new scheme, the global distribution of frequency of occurrence of supersaturated regions compares well with remotely sensed microwave limb sounder (MLS) data, with the most marked errors of underprediction occurring in regions where the model is known to underpredict deep convection. Finally, it is also demonstrated that the new scheme leads to improved predictions of permanent contrail cloud over southern England, which indirectly implies upper-tropospheric humidity fields are better represented for this region. Copyright (c) 2007 Royal Meteorological Society
\end{abstract}

KEY WORDS cirrus clouds; ice nucleation; microphysics

Received 9 May 2006; Revised 21 August 2006; Accepted 23 August 2006

\section{Introduction}

While clouds are commonly cited as an important but ill-understood component of atmospheric models of all spatial and temporal scales, it is ice cloud processes that are the least understood. It is only very recently that initial attempts have been possible to supplement in situ (and thus extremely sparse) aircraft data (e.g. Heymsfield et al., 1998) with global remotely sensed observations of basic ice cloud information such as the ice water content or crystal habits (e.g. Rädel et al., 2003; Li et al., 2005).

One of the complexities of ice clouds is that, unlike liquid water clouds, the ice nucleation process in the atmosphere can occur via both homogeneous and heterogeneous pathways (Pruppacher and Klett, 1997), with the latter further subdivided into a number of nucleation mechanisms. This work only considers the former homogeneous process, which is supposed to dominate cirrus cloud formation in the presence of moderate or stronger updraughts, or in relatively pristine environments with few ice condensation nuclei present (Spice et al., 1999; Lin et al., 2002; Gierens, 2003; Ren and Mackenzie, 2005). The lack of consideration of a plethora

* Correspondence to: A. M. Tompkins, ECMWF, Shinfield Park, Reading, Berkshire RG2 9AX, UK. E-mail: tompkins@ecmwf.int of heterogeneous processes is noted as a caveat in this work.

Ice crystal nucleation contrasts sharply with the equivalent process for liquid cloud droplets, since the nucleation process is not activated at small supersaturations with respect to the ice saturation vapour pressure. At low temperatures, where the difference between the liquid water and ice saturation vapour pressures is large, the relative humidity (RH) with respect to ice can exceed $150 \%$ before the onset of the nucleation process, and supersaturations with respect to ice are commonly observed by in situ and remote-sensing techniques (e.g. Heymsfield et al., 1998; Gierens et al., 1999, 2000, 2004; Spichtinger et al., 2003). This is illustrated schematically in Figure 1(a) which shows the hypothetical evolution of an upper-troposphere parcel of air subjected to adiabatic cooling, illustrating that RH increases until a critical threshold, $R H_{\text {crit }}$, is reached that can significantly exceed $100 \%$. At this critical value, ice crystals are homogeneously nucleated and their uptake of the excess water vapour prevents the RH from rising much past $R H_{\text {crit }}$, and in fact the RH then reduces towards a value that in most cases just exceeds the $100 \%$ level. The depositional growth time-scale may be shorter or longer than the model time step, but is however generally short compared to the time required to reach the critical value needed to initiate nucleation. It is clear that the zero-order effect 

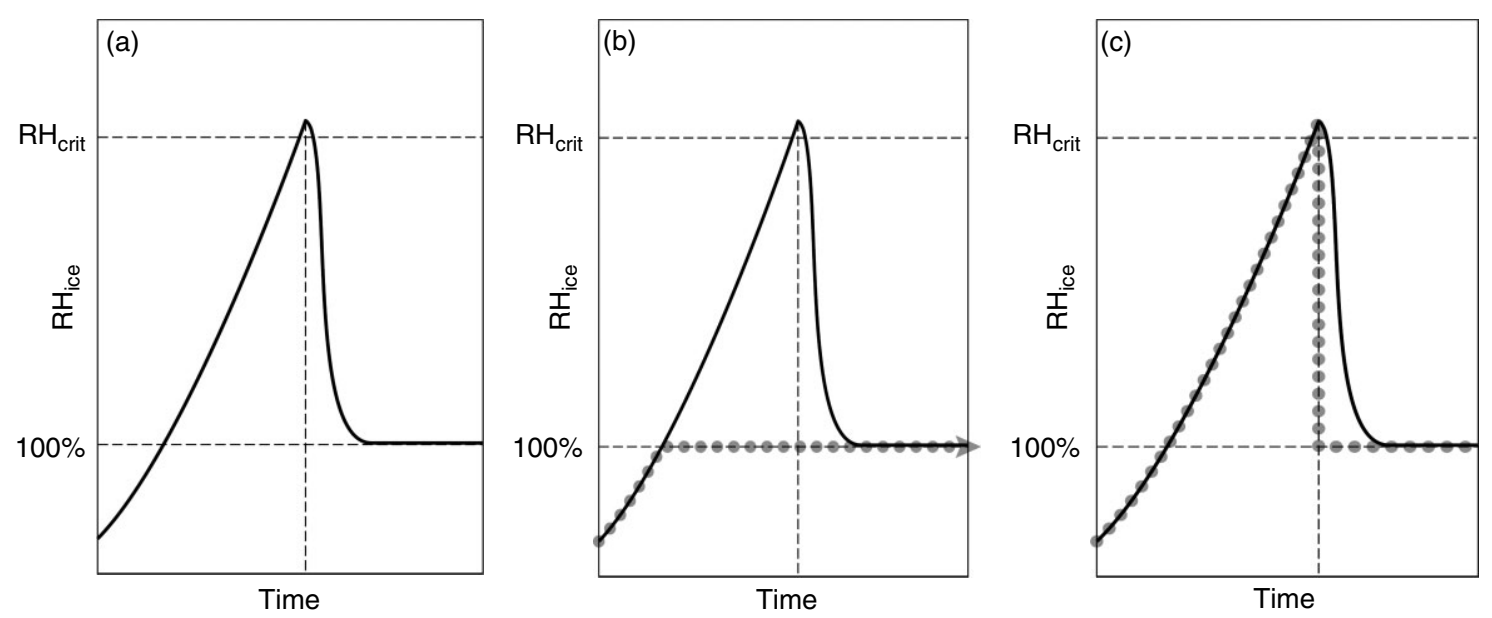

Figure 1. (a) Schematic (adapted from Lohmann and Kärcher, 2002) of the evolution of RH in a hypothetical parcel subject to adiabatic cooling at low temperatures $(T<235 \mathrm{~K})$. In (b), a dotted line is added to indicate the approximation of this process by the operational ECMWF IFS code. The present scheme does not allow RH to exceed $100 \%$, and any excess humidity is instantaneously converted to ice. (c) outlines the new simple parametrization described in this paper. The new scheme allows supersaturation to occur and thus represents the hysteresis in the ice cloud behaviour. However, the scheme does not attempt to explicitly model the nucleation and depositional growth processes, and converts all humidity exceeding the saturation value to ice instantaneously once the nucleation threshold is attained. It should be emphasised that the scheme attempts to ascertain how much of the grid box has reached this threshold and the adjustment only occurs inside this cloudy region of the grid box. Thus grid-mean supersaturated states can be maintained even in grid boxes that contain some ice.

of modelling the ice nucleation process explicitly is that significant supersaturation in a model grid cell is possible.

Many models currently treat the ice phase similarly to warm-phase microphysical processes, in that supersaturation is immediately converted to ice crystals. The Integrated Forecast System (IFS) of the European Centre for Medium-Range Forecasting (ECMWF) is one such model (Figure 1(b)). It is to be expected that such models will suffer from upper-troposphere dry biases and underestimate humidity temporal and spatial variability. Ovarlez and van Velthoven (1997) and Ovarlez et al. (2000) show this to be the case for earlier versions of the IFS. In order to rectify this shortcoming in the IFS ice microphysics, this paper outlines a simple parametrization which modifies a saturation-adjustment-type scheme in the ECMWF IFS in order to take the nucleation process into account consistently with the assumptions concerning the grid cloud cover.

\section{Homogeneous nucleation in large-scale models}

Relative to heterogeneous ice nucleation, the homogeneous nucleation process is reasonably well understood. Classical theory and controlled laboratory experiments have documented the critical vapour saturation mixing ratio with respect to ice at which homogeneous ice nucleation initiates (Pruppacher and Klett, 1997; Koop et al., 2000). This work adopts the supersaturated RH threshold, $R H_{\text {crit }}$, using the empirical approximation of the results of Koop et al. (2000) given by Kärcher and Lohmann (2002), which is a function of temperature and ranges from $45 \%$ supersaturation at $T=235 \mathrm{~K}$ to $67 \%$ at $T=190 \mathrm{~K}$. Since the IFS only has one cloud water variable, $\mathrm{RH}$ is calculated with respect to liquid water in the warm phase $(T>273 \mathrm{~K})$ and with respect to ice when temperatures are lower than $250 \mathrm{~K}$. Between these values it is interpolated according to Simmons et al. (1999). However, since this work considers pure ice phase clouds only, RH refers to the ice-saturated value throughout.

This threshold is a local condition, describing nucleation in a well-mixed parcel of air of unspecified dimensions. It is unlikely to apply to a general-circulation model (GCM) with grid cell sizes spanning $\mathrm{O}(100 \mathrm{~km})$ in the horizontal and of finite vertical dimension. This is because, over such a spatial scale, water vapour and temperature are likely to vary considerably. Thus the critical threshold for ice formation may be exceeded locally within the grid cell, while the grid mean values imply that clear-sky conditions predominate. Therefore, to accurately model the ice nucleation process, knowledge of subgrid fluctuations are required.

A number of so-called statistical schemes are able to provide such information explicitly (e.g. Smith, 1990; Bony and Emanuel, 2001; Tompkins, 2002). However, most GCMs that do not have explicit representation of subgrid variability are still able to provide some information, the most basic of which is the provision of a fractional cloud cover, which determines exactly what portion of the grid cell contains cloud condensates and thus is subject to microphysical processes.

The fact that microphysics processes are only operating in the cloudy portion of the grid box presents a dilemma if one wishes to represent ice nucleation processes accurately. Outside the cloudy area, highly supersaturated states may be maintained, while deposition can rapidly (i.e. quickly in comparison with a typical GCM model time step) deplete available supersaturation within the cloudy region. To model this accurately in a GCM from time step to time step, a memory of the humidity both inside and outside the cloudy region is necessary. 
With only one prognostic equation usually used in GCMs for the grid-mean humidity, this means that either an additional prognostic equation is required (the environmental humidity for example), or simplifying diagnostic assumptions (a diagnostic parametrization) need to be applied to divide the grid-mean humidity between the cloudy and clear-sky portions.

Previous schemes have used a variety of approaches to do this, outlined in Table I. All of these approaches suffer from a common drawback, which is illustrated with the example of the Lohmann and Kärcher (2002) scheme, which makes the simplest assumption that the environmental humidity equals the grid-averaged value. We imagine a grid box that is half covered by cloud at a certain point in time and for which the humidity everywhere inside the grid cell (both inside and outside the cloud) is exactly equal to the grid-mean value, which is assumed ice supersaturated. Inside the cloud, ice crystals will grow at the expense of the supersaturation, and humidity will be depleted. Thus, at the subsequent time step, the environmental humidity should exceed the in-cloud value, neglecting all other processes. However, since the scheme lacks a memory for this process, one must resort to the diagnostic assumption of equal humidity in the clear-sky and cloudy portions. This equates to an artificial horizontal flux of humidity from the clear-sky to the cloudy portion of the domain. In fact, the implemented Lohmann and Kärcher (2002) scheme avoids this by resorting to the use of a cloud cover that is either zero or one when RH $>100 \%$. If subsaturated conditions subsequently occur, the diagnostic partial cloud cover formulation is resumed (Lohmann and Roeckner, 1996), and the in-cloud humidity is assumed to equal the saturation value.

When each of the existing schemes in Table I are considered in the context of microphysical processes, it is apparent that each features such a subgrid horizontal water vapour flux. It should be emphasised that this is not an inconsequential aspect of these schemes. The performance of the Met Office Unified Model is found to be critically sensitive to this assumption concerning humidity (D. Wilson, personal communication). Likewise, the ECMWF model Hamburg version (ECHAM) scheme avoids this artificial flux by disallowing partially cloudy conditions and reverting to an all-or-nothing assumption of either overcast or clear-sky conditions when supersaturation is allowed (U. Lohmann, personal communication).

\section{New scheme for the IFS}

A simple (i.e. with no new prognostic equations) scheme is presented which is tested in the ECMWF IFS model. It attempts to represent the ice supersaturation and the homogeneous nucleation process in the IFS while excluding artificial horizontal water vapour transport on the subgrid-scale.

The scheme assumes the following:

(1) Ice nucleation initiates when the supersaturation locally reaches the threshold specified by Kärcher and Lohmann (2002).

(2) As in the Tiedtke (1993) scheme, the clear-sky humidity fluctuations are assumed to be uniformly distributed with a fixed constant variance. Thus nucleation can occur when the grid-mean RH exceeds a threshold that is lower than the local criterion.

(3) Once ice is present, the deposition process is sufficiently rapid relative to a GCM time step that it can be approximated by a diagnostic adjustment to exactly saturated conditions inside the cloud.

A schematic summary of assumptions (1) and (3) on which the new scheme is based is shown in Figure 1(c). This schematic portrays the evolution of a homogeneous air parcel, and thus does not represent point (2) which concerns the subgrid variability issue.

The main difference from existing schemes is the choice of assumption (3), which appears to be reasonably justified in a wide range of updraught situations by modelling of the homogeneous nucleation process (Khvorostyanov and Sassen, 1998). The advantage of the above set of assumptions is that no artificial flux of humidity is permitted between clear-sky and cloudy regions. The obvious drawback is that clouds may not exist in subsaturated conditions, since by definition $q_{\mathrm{v}}=$ $q_{\mathrm{s}}$ (see Table I for definitions) within any part of the

Table I. Diagnostic assumptions used by various schemes that aim to represent ice supersaturated states.

\begin{tabular}{lcc}
\hline Scheme & Environment humidity $q_{\mathrm{v}}^{\mathrm{e}}$ & In-cloud humidity $q_{\mathrm{v}}^{\mathrm{c}}$ \\
\hline $\begin{array}{l}\text { ECHAM4 } \\
\text { (Lohmann and Kärcher, 2002) }\end{array}$ & $q_{\mathrm{v}}$ & $q_{\mathrm{v}}$ \\
$\begin{array}{l}\text { Met Office Unified Model PC2 } \\
\text { (Wilson and Forbes, 2004) }\end{array}$ & $C \times R H_{\text {crit }} q_{\mathrm{s}}+(1-C) q$ & $\left\{q-(1-C) q_{\mathrm{v}}^{\mathrm{e}}\right\} / C$ \\
$\begin{array}{l}\text { Gierens (unpublished) } \\
\text { New parametrization }\end{array}$ & $q_{\mathrm{v}}+q_{\mathrm{i}}$ & $q_{\mathrm{v}}-q_{\mathrm{i}}(1-C) / C$ \\
\hline
\end{tabular}

$q_{\mathrm{v}}, q_{\mathrm{i}}$ and $q_{\mathrm{s}}$ represent the grid-mean vapour, ice and saturation (with respect to ice) mixing ratios, respectively, while $q_{\mathrm{v}}^{\mathrm{e}}$ represents the 'environmental' humidity, i.e. the humidity in the clear-sky portion of the grid point. A pure ice phase cloud is presumed, thus liquid water is neglected. $\mathrm{C}$ is the fractional cloud cover. 
grid box with cloud condensate present, and no information concerning the ice crystal number concentration is available.

Given the parametrization assumption (3), the assumption that the in-cloud humidity is equal to the saturation value $q_{\mathrm{s}}$ allows one to derive the clear-sky 'environmental humidity', $q_{\mathrm{v}}^{\mathrm{e}}$, that is given in Table I:

$$
q_{\mathrm{v}}^{\mathrm{e}}=\frac{q_{\mathrm{v}}-C q_{\mathrm{s}}}{1-C} .
$$

This derivation for $q_{\mathrm{v}}^{\mathrm{e}}$ is familiar since it is already assumed by the operational Tiedtke scheme (Jakob, 2000). However, the subtle difference in the new scheme is that the grid-mean humidity is now allowed to exceed the saturated value in the pure-ice phase. Previously, $q_{\mathrm{v}}^{\mathrm{e}}$ was constrained to be less than the saturated value, while the new scheme allows the humidity in the clear-sky portion to exceed that in the cloudy portion of the domain (as indeed it must do if the grid mean is supersaturated). With this assumption therefore, the clear-sky 'memory' of humidity is retained through the separate prognostic evolution of the cloud cover.

If a cooling or other thermodynamic process increases the clear-sky humidity beyond the nucleation threshold specified by Kärcher and Lohmann (2002), the cloud cover, $C$, is appropriately increased. Practically, the scheme calculates the increase in cloud cover resulting from a temperature decrease $\Delta T$ by assuming that the clear sky humidity distribution is uniformly distributed:

$$
\Delta C=-(1-C) \frac{\left(\mathrm{d} q_{\mathrm{s}} / \mathrm{d} T\right) \Delta T}{2\left(R H_{\text {crit }} q_{\mathrm{s}}-q_{\mathrm{v}}^{\mathrm{e}}\right)} .
$$

Jakob (2000) gives more details of this derivation, correcting the erroneous derivation given in Tiedtke (1993). The associated change in ice mass mixing ratio corresponding to the assumed uniform humidity distribution is

$$
\Delta q_{\mathrm{i}}=0.5 \Delta C \frac{\mathrm{d} q_{\mathrm{s}}}{\mathrm{d} T} \Delta T .
$$

The factor 0.5 relates directly to the assumed uniform distribution for clear-sky humidity since, given a cooling of $\Delta T$, the region that undergoes nucleation will exceed the nucleation threshold by an amount ranging between zero and $\left(\mathrm{d} q_{\mathrm{s}} / \mathrm{d} T\right) \Delta T$. This term only operates when $q_{\mathrm{v}}^{\mathrm{e}}>K \times R H_{\text {crit }} q_{\mathrm{s}}$, (where the constant $K$ is set to 0.8 throughout most of the troposphere), in other words when the RH exceeds $80 \%$ of the threshold for nucleation. The value of $80 \%$ is a fixed diagnostic assessment of the horizontal temperature and humidity variability of the atmosphere. In the temperature range in which all cloud is assumed pure ice cloud in the IFS $(T<250 \mathrm{~K})$, the $R H_{\text {crit }}$ is set to the minimum of the critical supersaturated threshold given by Kärcher and Lohmann (2002) and the saturation mixing ratio with respect to liquid water. For higher temperatures, $R H_{\text {crit }}=1$, and the cloud source term reverts to the default scheme.
This change in ice mass will leave the in-cloud humidity in a supersaturated state, since it will only reduce the in-cloud total to the threshold for ice nucleation. The scheme assumes that the deposition time-scale is fast compared to a model time step, which is achieved by reducing the grid-mean humidity to the limit of

$$
q_{\mathrm{v}}^{\max }=q_{\mathrm{s}}\left\{C+(1-C) R H_{\text {crit }}\right\} .
$$

This clipping term has the effect of reducing the incloud humidity to the saturated value within one time step. Again, with $R H_{\text {crit }}$ equal to unity when $T>250 \mathrm{~K}$, the default clipping to the saturation value is used.

\section{Results}

\subsection{Model climate impact}

Two 7-member ensembles of 13-month T95 (approximately $210 \mathrm{~km}$ equivalent resolution) model integrations are conducted to investigate the effect of the modified cloud scheme, initialized on 1 August 2000. The first month of each integration is discarded, and the statistics are averaged over the last 12 months of each ensemble member, giving a total of seven years. The control integration uses the cloud scheme of model cycle 31r1 (operational in 2006), with the supersaturation scheme switched off.

In terms of the model cloud climatology, the largest sensitivity was not in the total column ice water (TCIW, sometimes referred to as the ice water path) but rather the total cloud cover. Figure 2 shows that the high-cloud cover is reduced by the new scheme, as expected, since humidity must now attain higher values to initiate cloud formation. Compared to the relative reduction in highcloud cover of $15 \%$ (or $6 \%$ absolute decrease), the global reduction in TCIW is much more modest at only $3.5 \%$. Using ISCCP D2 retrievals of total cloud cover (Rossow and Schiffer, 1991, 1999) as a benchmark, the control model tended to slightly but consistently overestimate the total cloud cover throughout the deep convective areas in the tropics, especially over the Pacific and Indian Oceans (Tompkins et al., 2004; Jung et al., 2005). With the reduction in cloud cover associated with the new scheme, the biases are improved throughout the tropics (not shown), although one should guard against drawing firm conclusions from such diagnostics, since cloud cover biases in the model are the result of an array of compensating errors in the cloud and other moist physics components.

The lower sensitivity of the ice water content relative to that of the high-cloud cover can be understood in terms of the relationship of the two metrics to the total water RH $\left(R H_{\mathrm{t}}=\left(q_{\mathrm{v}}+q_{\mathrm{i}}\right) / q_{\mathrm{s}}\right)$. In the default model where supersaturation is not allowed, clouds are initiated at much lower values of RH and equivalently $R H_{\mathrm{t}}$, relative to the new scheme. Cirrus clouds will therefore occur more rarely in the new scheme. However the sensitivity of the ice water path will be lower since, once the higher 


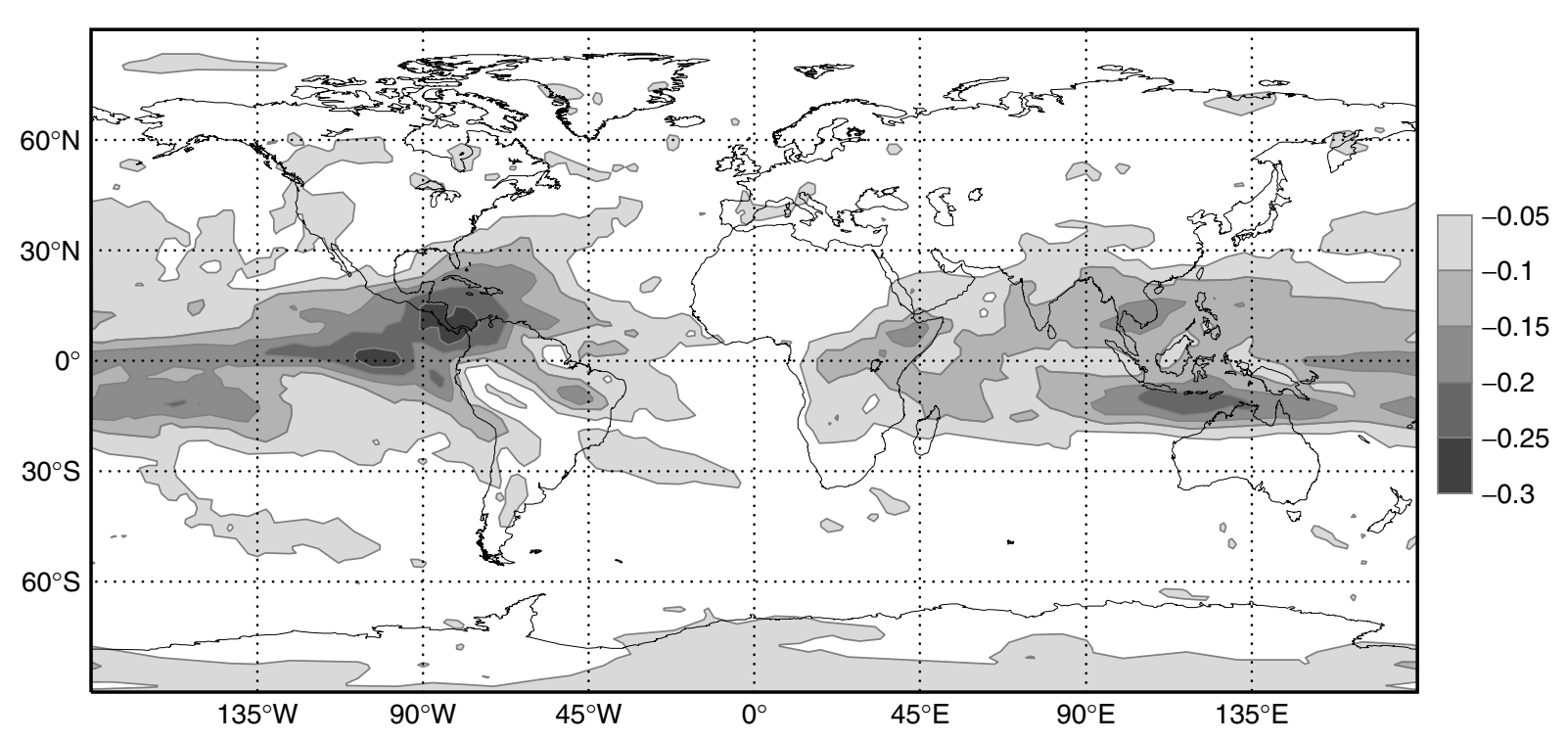

Figure 2. Mean difference in high-cloud cover ( $p<450 \mathrm{hPa}$ approximately) between two experiments using the new nucleation parametrization and the control (both over a 7-member ensemble and 12 months).

threshold is reached in the new scheme, all of the water vapour exceeding the saturation mixing ratio is rapidly converted to ice, thus the ice content of these clouds is ultimately more similar.

This can be illustrated with a straightforward scenario of two adjacent grid boxes in the upper atmosphere with a temperature such that the critical $\mathrm{RH}$ for homogeneous nucleation is $140 \%$. Starting from dry conditions, vertical motion causes grid boxes 1 and 2 to attain $R H_{\mathrm{t}}=1.2$ and 1.8 , respectively. With the default model, both grid boxes become overcast, while with the new parametrization only grid box 2 becomes overcast. Therefore the cloud cover is $50 \%$ less with the new scheme. However, the evolution of the ice is not the same. Once the total water exceeds the modified threshold of $R H=140 \%$ in the second grid box, the nucleation process immediately converts all the water vapour exceeding the saturation mixing ratio to ice, thus the final ice mass is identical with the default model and the new scheme in this grid box. Therefore it is clear that the total ice mass averaged over the two grid boxes only reduces by $20 \%$ with the new scheme in this simple hypothetical example, i.e. less than the $50 \%$ cloud cover reduction. Precipitation processes will further exacerbate these differences, since precipitation production reduces the cloud ice and thus also cloud ice differences, while it leaves the cloud fraction unaltered in the Tiedtke (1993) scheme.

The impact of the supersaturation scheme on the humidity field is shown as a zonal mean difference in $\mathrm{RH}$ in Figure 3. As expected, the scheme increases $\mathrm{RH}$ in the upper troposphere and also influences the lower stratosphere through increased cross-tropopause transport. The absolute increases in zonal mean RH are mostly in the range of 5 to $10 \%$, with the peak of approximately $20 \%$ occurring in the troposphere/stratosphere transition zone above the main deep convective detrainment level in the tropics. The peak in the tropics between the radiative and temperature tropopauses is expected since in this zone the atmosphere is subjected to gentle ascent, the diabatic cooling of which balances the small radiative heating. Further comments on the impact on the humidity field are given below.

The net effect of the changes in cloud properties in the tropics (latitudes less than $30^{\circ}$ ) is an increase in net outgoing long-wave radiation of $2.1 \mathrm{~W} \mathrm{~m}^{-2}$ and a similar compensating increase of $2.2 \mathrm{~W} \mathrm{~m}^{-2}$ in net incoming short-wave radiation, while the corresponding global figures are 1.3 and $1.5 \mathrm{~W} \mathrm{~m}^{-2}$, respectively.

\subsection{Comparison to MOZAIC aircraft data}

The humidity fields in the two year-long integrations described above are compared to aircraft data from the Measurement of Ozone and Water Vapour by Airbus Inservice Aircraft (MOZAIC) campaign, which compiled many years of in situ aircraft measurements taken by commercial aircraft carrying research-quality instrumentation (Gierens et al., 1999). A third experiment, using an intermediate modified scheme, is conducted to aid the understanding of the results. In this experiment, supersaturation is permitted by simply increasing the ice saturation mixing ratio used in the cloud scheme to the critical value given by Koop et al. (2000). In other words, the saturation clipping limit is replaced by $R H_{\text {crit }} q_{\mathrm{s}}$ in the ice phase, with cloud formation commencing when the gridmean humidity exceeds $K \times R H_{\text {crit }} q_{\mathrm{s}}$. Ice crystal growth in this case can only reduce the humidity back to this higher critical value.

The model integrations are validated in terms of normalized probability density functions (PDFs) of RH (with respect to ice), which are compared to the MOZAIC climatological PDFs given by Gierens et al. (1999). Results are shown at the $250 \mathrm{hPa}$ level for the Northern Hemisphere (north of $20^{\circ} \mathrm{N}$ ), using the last month of the 


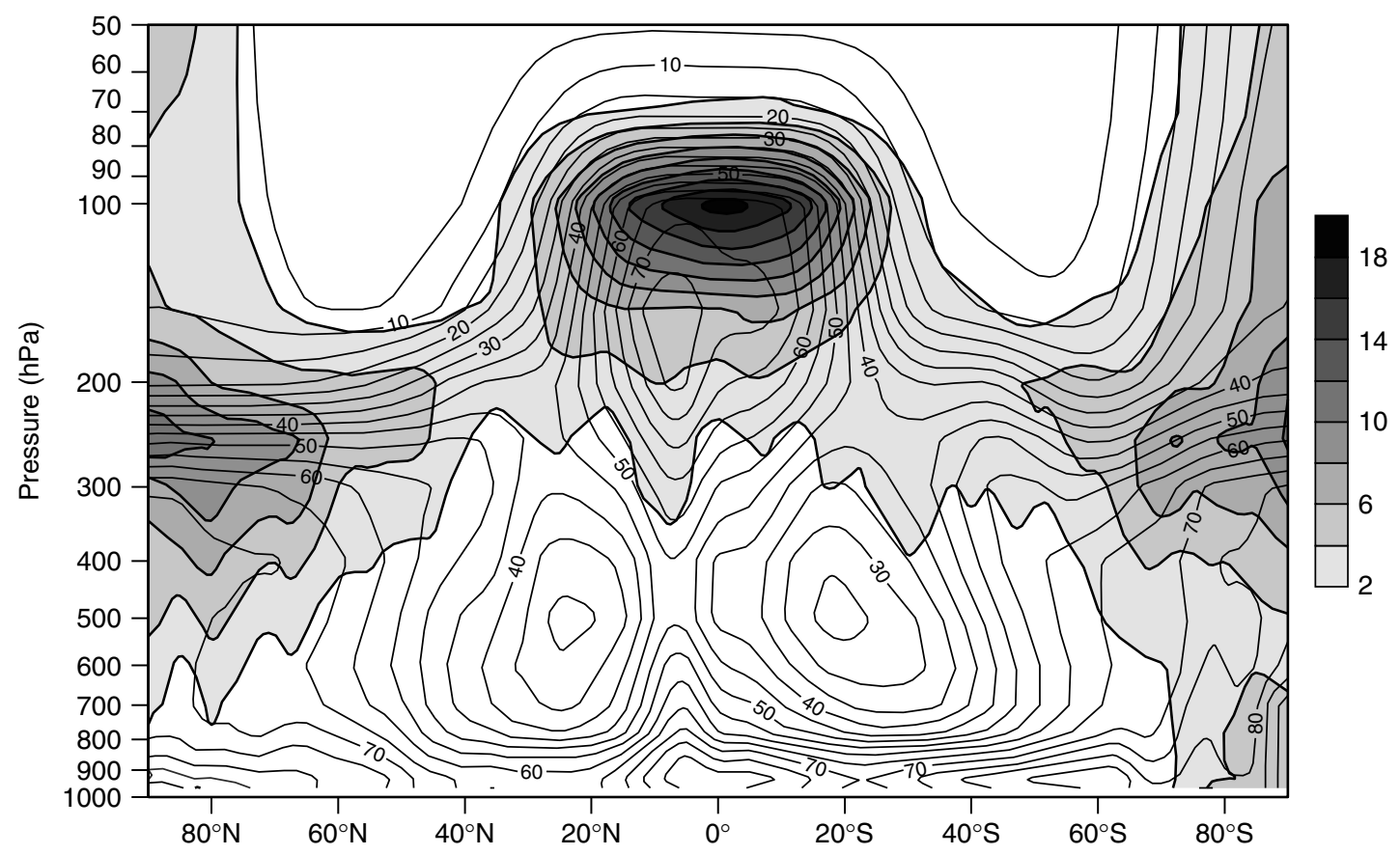

Figure 3. Zonal mean difference in RH (shaded contours, see key) between two experiments using the new nucleation parametrization and the control (both averaged over 7 ensemble members and 12 months). The unshaded contours give the RH in the control forecast, with contour interval $5 \%$.

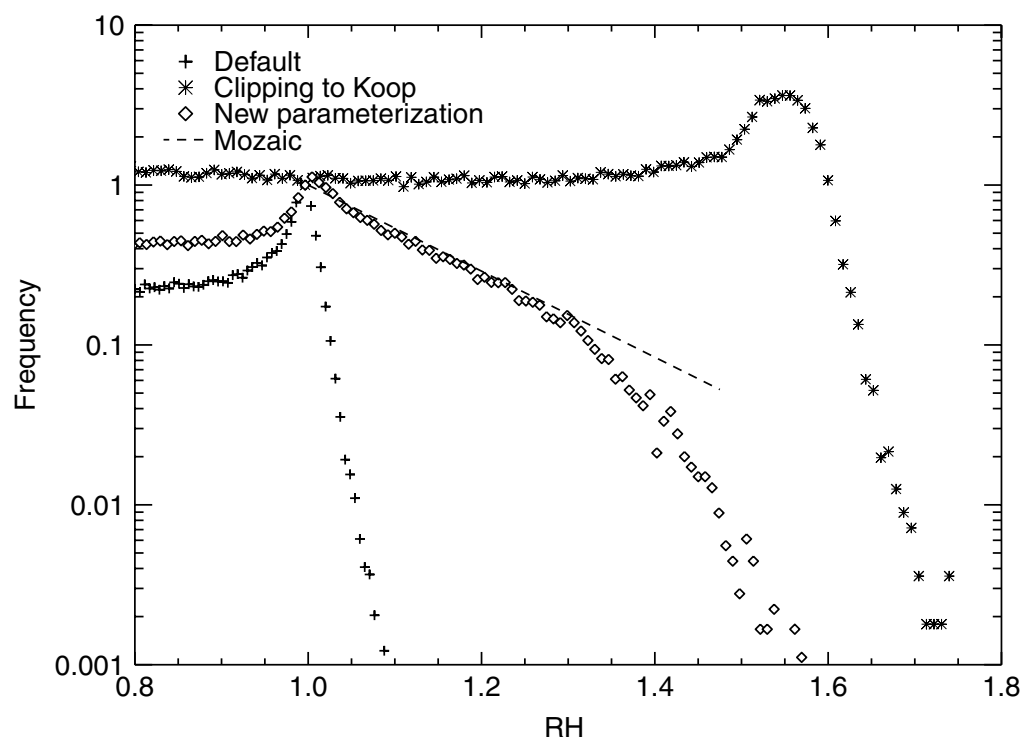

Figure 4. Normalized PDF of RH at the $250 \mathrm{hPa}$ level for the Northern Hemisphere from a single 12-month integration. (RH is expressed as a fraction of $100 \%$.) Models and observations are identified in the legend.

climate integrations, with data archived once daily. All PDFs are normalized such that $P D F(R H=100 \%)=1$.

Figure 4 compares the new scheme to the default model. The default model behaves as expected, with a sharp mode around $R H=100 \%$ due to the fact that this limit cannot be exceeded in cloudy air masses. There is a slight overshoot with $\mathrm{RH}$ attaining values up to almost $10 \%$ supersaturation. This is a purely numerical effect and, among other causes, is the result of the clipping to saturation in the model not being performed at exact 'end of time step' temperature and humidity profiles with semi-Lagrangian dynamics in use. The third experiment with the increased nucleation threshold responds as expected, with the PDF shifted to the right and a broader mode existing around the 50 to $60 \%$ supersaturation appropriate for this pressure level. The mode is broader than the control due to the additional dependence of $R H_{\text {crit }}$ on temperature.

The new parametrization produces a PDF of RH that lies somewhere between these two extremes. After the smaller $100 \%$ mode, the data follow the best-fit line to the observations made in the MOZAIC campaign. 
However, at a supersaturation of around $30 \%$, the PDF becomes steeper than the observations, i.e. relative to the frequency of occurrence at $100 \% \mathrm{RH}$, fewer grid points attain high values of RH. This scale break did not occur in the scheme of Lohmann and Kärcher (2002) which reproduced the aircraft data well out to the observed limit of around $160 \% \mathrm{RH}$. This disparity between the two models can be explained by the their treatment of subgrid-scale variability.

It is recalled that the grid-box mean humidity is used to initiate ice nucleation in the Lohmann and Kärcher (2002) scheme and that the grid box remains clear until the nucleation threshold is reached, at which point it becomes completely cloudy. This implies that subgrid variability is neglected. Instead, the IFS model makes a very simple assumption that ice nucleation occurs when the humidity reaches $80 \%$ of the critical threshold for ice nucleation. This value of $80 \%$ is a fixed assessment of the variance of the subgrid humidity distribution. Taking $80 \%$ of the average critical nucleation threshold of roughly $160 \%$ supersaturation gives a scale-break prediction of $130 \%$, approximately that seen. A higher threshold value than $80 \%$ is associated with less humidity variability, with the limit of $100 \%$ corresponding to homogeneous subgrid humidity and consequentially no scale break, as in the Lohmann anf Kärcher (2002) scheme. Analysis of the 150 and $200 \mathrm{hPa}$ levels produced similar results (not shown).

\subsection{Comparison to microwave limb sounder data}

A useful additional source of information concerning ice supersaturation is provided by MLS retrievals. Although the horizontal and vertical resolution is coarser than the in situ aircraft data, the retrievals have the advantage of global coverage, in particular allowing inspection of the tropical upper troposphere.

The model is compared to MLS retrieval climatology obtained between September 1991 and June 1997. The retrieval methodology is described by Read et al. (2001) and analysed in detail in terms of frequency of occurrence of supersaturated regions by Spichtinger et al. (2003). The retrievals are gridded to a horizontal resolution of approximately $300 \mathrm{~km}$, and have a vertical resolution of $3 \mathrm{~km}$. As in Spichtinger et al. (2003), only the pressure levels of $147 \mathrm{hPa}$ and $215 \mathrm{hPa}$ are analyzed due to the increasing reduction in reliability lower in the troposphere. The model data are taken from the nearest vertical model level to these pressures from the same long-term climate run described in the previous section. While the original data are cloud-cleared, the model data are used from all points with cloud cover less than 95\%, since the frequency of occurrence is not affected by the presence of clouds in the grid box if it is not overcast.

Maps of the annual mean frequency of occurrence of ice supersaturated regions (ISSRs) at the $147 \mathrm{hPa}$ level are shown in Figure 5. Figure 5(b) repeats Figure 1 of Spichtinger et al. (2003) and, as they pointed out, the maximum values occur in the tropics as expected, with peaks over the deep convective regions of the tropical western Pacific, Africa and the Americas.

Figure 5(a) shows that the model reproduces the general frequency of occurrence well, with peak values in the tropics and the secondary peak over the South Pole. The model biases (Figure 5(c)) can be summarized as a slight underestimation of ISSR frequency over the western Pacific, a corresponding overestimation over the Indian Ocean and the warm tongue in sea surface temperature over the eastern Pacific, and a significant underestimation over continental Africa and the Americas.

The striking aspect of the ISSR frequency biases is that they reflect precisely the known biases in the model's over- or underestimation of tropical deep convection (Tompkins et al., 2004). Comparison of rainfall with Global Precipitation Climatology Project data (Huffman et al., 1997), top-of-atmosphere infrared and solar net fluxes with Clouds and the Earth's Radiant Energy System data (Wielicki et al., 1996), and ice mixing ratios with MLS retrievals (Li et al., 2005), all point to the same major errors in the tropics, in particular the underestimation of deep convective activity over tropical America and Africa (not shown).

This points towards a mechanism for creating the tropical ISSRs whereby deep convection locally transports water vapour to the region of the radiative tropopause (where radiative heating rates are zero) which is then transported upwards towards the temperature tropopause by slow mean ascent which balances the small net radiative warming. Where the model locally produces too little deep convection, the radiative tropopause is too dry, reducing the instance of ISSRs in the tropopause transition layer.

To summarize the model performance regionally, Table II gives a direct comparison with Spichtinger et al. (2003) of regionally averaged supersaturation frequencies at both 147 and $215 \mathrm{hPa}$. The model results are taken from the nearest level in the vertical to these pressures to avoid vertical interpolation. Comparison of the model output at the adjacent levels gives an absolute error estimate for the neglect of vertical interpolation in the global frequency of $0.02 \%$. The impact of the cloud mask implementation is $0.8 \%$ at $147 \mathrm{hPa}$.

The figures confirm that the geographical variation in supersaturation frequency is broadly captured, but with a significant underestimation in the Tropics and over Antarctica. In contrast, the model has a smaller variation in height than the MLS data, and thus overestimates the supersaturation frequency at the lower level of $215 \mathrm{hPa}$. One caveat is that the MLS retrievals become less reliable at lower levels in the atmosphere.

\subsection{Comparison to contrail observations}

Since the new parametrization aims to improve the representation of supersaturation in the humidity field at low temperatures, it is likely and desirable that more accurate predictions of occurrence of persistent aircraft 

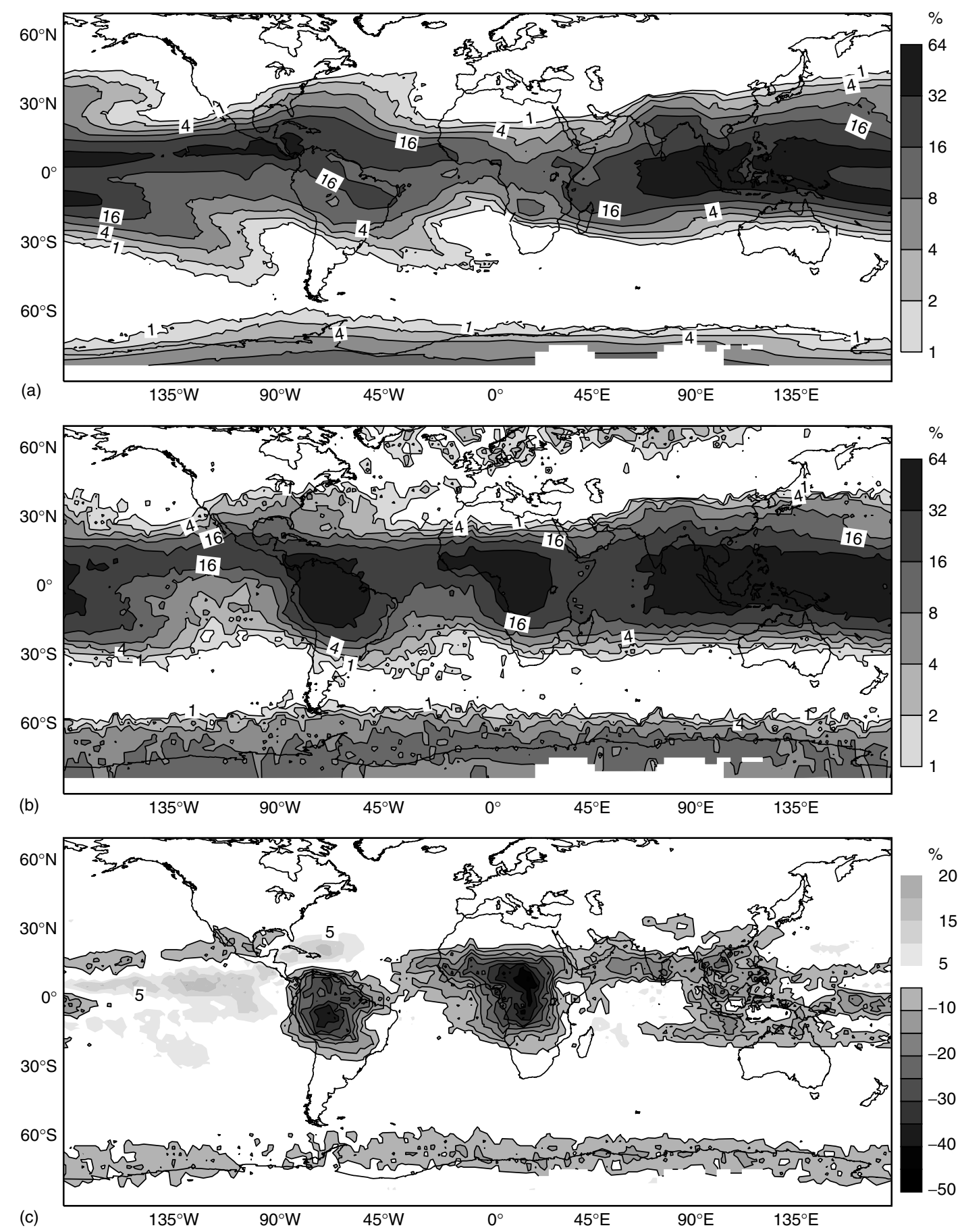

Figure 5. Frequency of occurrence (\%) of ice supersaturation from (a) the 7-member climate ensemble 12-month average, and (b) the MLS retrievals. (c) shows the difference field.

Table II. Frequency of occurrence (\%) of ice supersaturation for the model and MLS retrievals.

\begin{tabular}{llrrrrr}
\hline \multirow{2}{*}{ Area } & Latitude range & \multicolumn{2}{c}{$147 \mathrm{hPa}$} & & \multicolumn{2}{c}{$215 \mathrm{hPa}$} \\
\cline { 3 - 4 } & & Model & MLS & & Model & MLS \\
\hline Global & $90^{\circ} \mathrm{S}-90^{\circ} \mathrm{N}$ & 7.8 & 10.5 & & 8.6 & 4.3 \\
Northern Hemisphere & $>30^{\circ} \mathrm{N}$ & 0.7 & 0.9 & & 5.9 & 2.2 \\
Tropics & $30^{\circ} \mathrm{N}-30^{\circ} \mathrm{S}$ & 14.4 & 18.9 & & 11.0 & 6.0 \\
Southern Hemisphere & $30^{\circ} \mathrm{S}-55^{\circ} \mathrm{S}$ & 0.5 & 0.3 & 6.3 & 2.5 \\
Antarctic & $>55^{\circ} \mathrm{S}$ & 2.2 & 6.1 & 6.0 & 6.1 \\
\hline
\end{tabular}

MLS data are taken from Spichtinger et al. (2003) at pressure levels 147 and $215 \mathrm{hPa}$.

Model results are taken at the nearest pressure levels (144 and $211 \mathrm{hPa}$, respectively). 
condensation trails (contrails) should result. Contrails are recognised to influence the Earth's radiative budget by having a warming effect (IPCC, 1999), which, while currently minor, may become more important with future projections of increasing air traffic. Moreover, persistent contrails may spread out and form cirrus clouds that are difficult to distinguish from naturally formed clouds, and thus have a more important effect than currently estimated. In order to study these issues it is extremely important to have a model that does have skill to predict contrail formation and their persistence.

In order for contrails to form and persist for more than a few minutes, certain atmospheric conditions have to be fulfilled (Schumann, 1996; Jensen et al., 1998). The atmosphere at the altitude of the aircraft has to be supersaturated with respect to ice and the ambient air temperature has to be sufficiently low. The exact maximum temperature that allows contrail formation depends on engine parameters, pressure and ambient humidity. For our purpose here, however, it can be reasonably and simply assumed that $T$ must not exceed $233 \mathrm{~K}$, the approximate threshold for the onset of homogeneous nucleation of aqueous solution drops (Pruppacher and Klett, 1997).

Applying these two simple criteria using the default model and the new parametrization, a hit/miss prediction for the existence of persistent contrails is made. The predictions derive from six months of short-term forecasts, which are compared to a long-term dataset of local visual contrail observations, taken over Reading in southern UK. Weather conditions permitting, these observations have been taken since July 2004 on a quasi-regular basis, usually four times a day. Reading is particularly well suited to establish such a contrail database due to its geographical location at the entrance of the North Atlantic flight corridor. In this study, observations between August 2004 and January 2005 are used.

For the model validation, the contrail observations are divided into two categories: 'yes' events, where permanent/non-dissipating contrails were observed indicating supersaturated conditions, and 'no' events, where contrails either dissipated or were not observed. A statistical analysis has been performed by comparing both categories to the model predictions for contrail favourable or non-favourable atmospheric conditions. For this, a simple RH threshold is used of $R H_{\text {ice }}>99 \%$ and $T<233 \mathrm{~K}$, where $R H_{\text {ice }}$ and $T$ are obtained from a forecast initialized at 12 UTC at a forecast range between 20 to 30 hours to coincide with the exact observation time, for the grid box containing Reading. The threshold of $99 \%$ for $R H_{\text {ice }}$ was applied since the default model clips $R H_{\text {ice }}$ at $100 \%$, with the $1 \%$ difference allowing for inaccuracies in numerics and archiving.

When making the comparison, it is important to recall that the observation is made for the visible allsky hemisphere, which will not correspond to the same region as a model T511 gridbox with a resolution of approximately $40 \mathrm{~km}$. Moreover, the observation is classified as a 'hit' if a permanent contrail is visible anywhere in the sky. Horizontal (and indeed vertical) variability of humidity means that permanent contrails and ice subsaturated mean conditions may coexist within the observational domain, implying that a lower $\mathrm{RH}$ threshold may lead to increased contrail predictive skill. This effect is offset, on the other hand, by the reality that the observations will tend to under-report permanent contrails if the vertical location of supersaturated layers do not coincide with the discrete flight levels. Here only the single threshold is used for reasons of brevity, which is justifiable since two model versions are compared using this identical benchmark. While greater or lesser skill may be achieved with other thresholds, the sign of the sensitivity of the prediction skill to parametrization methodology is robust.

The result of each set of comparisons can be represented in a $2 \times 2$ contingency table, yielding the number of correct hits, $a$, false alarms, $b$, number of misses, $c$, and lastly the number of correct rejections, $d$. A possible method to compute the statistical significance of these results is the 'odds ratio', $R$, proposed by Stephenson (2000) for meteorological applications and defined as

$$
R=\frac{a \cdot d}{b \cdot c} .
$$

This metric is equal to unity if there is no correlation between prediction and observation, larger (smaller) than 1 for the case of a positive (negative) correlation. The natural logarithm of $R$ is asymptotically Gaussian distributed, with a standard deviation of

$$
\sigma=\sqrt{\frac{1}{a}+\frac{1}{b}+\frac{1}{c}+\frac{1}{d}} .
$$

The two contingency tables for the default model and the new parametrization are given in Table III. It can be seen that the new parametrization predicts persistent contrails more often than the default model; the hit rates $(a /(a+c))$ are 0.59 for the new parametrization and 0.45 for the default model, but also the false-alarm rate $(b /(b+d))$ increases from 0.14 to 0.19 . The odds ratio takes into account all this information and it increases from 4.8 (default) to 6.1 (new parametrization). The significance of this result can be tested by comparing it to the null hypotheses that the forecast and the observations are independent of each other with a $\log$ (odds) of zero.

Table III. $2 \times 2$ contingency tables for comparisons of visual contrail observations with predictions using the default model

\begin{tabular}{|c|c|c|c|c|c|}
\hline \multicolumn{3}{|c|}{ Default model } & \multicolumn{3}{|c|}{ New cloud scheme } \\
\hline & \multicolumn{2}{|c|}{ Predicted } & & \multicolumn{2}{|c|}{ Predicted } \\
\hline & yes & no & & yes & no \\
\hline $\begin{array}{l}\text { Observed } \\
\text { yes }\end{array}$ & 31 & 38 & $\begin{array}{l}\text { Observed } \\
\text { yes }\end{array}$ & 41 & 28 \\
\hline no & 12 & 71 & no & 16 & 67 \\
\hline
\end{tabular}
and the new parametrization. 
While the $\log$ (odds) of the forecast using the default model is 3.99 standard deviations away from zero, the corresponding value for the new parametrization is 4.89 . Hence, clearly an improvement in significance has been achieved.

\section{Conclusions}

First results are presented from a new and simple parametrization that attempts to represent ice supersaturation and the homogeneous ice nucleation process. The model contrasts with existing schemes in that it does not attempt to explicitly model the nucleation and deposition process. Rather it assumes that the process is fast compared to a GCM time step so that one can diagnostically perform an instantaneous adjustment to saturated conditions inside the cloud once nucleation initiates.

It is argued that, without an additional prognostic equation to provide the ability to separately map the evolution of the humidity within the cloud and in the environment, schemes that attempt to explicitly model the deposition process are forced to make a diagnostic assumption to distribute the grid-mean humidity between the cloud and clear-sky portions of the grid cell at each time step. The assumptions used in existing schemes were reviewed, and were seen to differ greatly, and can imply a significant and artificial horizontal flux of water vapour between the clear-sky and cloudy portions of the grid cell, which can consequently dominate the microphysical processes. It is therefore argued that, within the constraints of current schemes that do not implement a separate prognostic equation for in-cloud humidity, the scheme outlined here provides a simple alternative approach, albeit at the expense of not allowing ice crystals to exist in subsaturated conditions.

The main effect on the model climate of the new scheme is to reduce the high-cloud cover, most prominently in the tropics. The humidity field is also influenced, with the upper troposphere moistened globally with the new scheme, as expected.

Although crude, the new scheme agrees well with aircraft observations at the lower range of supersaturations (up to RHs of 120 to 130\%), while it underpredicts the occurrence of higher RH values, as indeed it should since the observations are collected at a smaller horizontal spatial scale. The threshold at which the model and aircraft observations begin to diverge is consistent with the simple assumptions the model makes concerning the subgrid fluctuations of humidity and temperature. In further support, it is shown that the new scheme also improves the prediction of permanent contrail occurrence over southern England in the medium-range forecasts.

MLS data retrievals of humidity were used to validate the model globally. Due to the dual complications of cloud clearing and the coarse retrieval resolution, these were compared using the straightforward frequency of occurrence of supersaturation. The new scheme was generally found to reproduce the geographical location and frequency of atmospheric supersaturation in the upper troposphere. The model biases notably reflected the established biases in deep convective activity in the tropics, which substantiates the view of deep convection transporting humidity locally to the radiative tropopause, which then undergoes slow widespread ascent through the transition zone to the temperature tropopause.

One notable omission from the validation exercises was a systematic comparison to the radiosonde network. The reason for this was the current lack of a general humidity bias-correction methodology for the diverse sonde types assimilated (uncorrected) into the ECMWF system. As of February 2006, many of the sondes assimilated were Vaisala RS80s, with a smaller number of the more recent RS90 and RS92 types. The Vaisala sondes are supplemented over the American continent by VIS sondes, while China, Russia, India and Japan all launch significant numbers of their own systems. The French MODEM platform is also widespread.

Taking the RS80 as an example, a number of studies have demonstrated a clear dry bias in the upper troposphere with this platform, and have offered and evaluated a range of bias-correction techniques (e.g. Soden and Lanzante, 1996; Wang et al., 2002; Soden et al., 2004; John and Buehler, 2005). A preliminary analysis with the new scheme showed that the moistening of the upper troposphere resulted in the model becoming too moist compared to the uncorrected sondes in the Southern Hemisphere. However, since the magnitude of the documented RS80 dry bias exceeds the humidity impact of the new scheme, this conclusion would reverse if a standard RS80 bias correction were applied. The differences between different sonde platforms, and thus their uncertainty, is far greater still. Even the very recent RS92 sonde, which possesses a new pulse-heated twin sensor arrangement to prevent sensor icing (Miloshevich et al., 2006), has a day/night radiation bias magnitude that exceeds the changes implied by the new model physics in midlatitudes (John and Buehler, 2005; Miloshevich et al., 2006). It is therefore a recommendation of this work that further attempts be made to monitor and quantify the magnitude of upper-tropospheric humidity biases for each common radiosonde type, and if possible subsequent steps taken to apply a suitable radiosonde bias correction in the data assimilation system at ECMWF.

\section{Acknowledgements}

The first author would express his appreciation to both Ulrike Lohmann (ETH, Zurich) and Damian Wilson (Met Office, UK) for their insightful comments and many vigorous discussions that have focused on the merits of the various approaches to cloud parametrization during visits to their respective host institutes. Further discussions with Bernd Kärcher, Keith Shine and Peter Spichtinger were also much appreciated, and PS also provided the processed MLS data. This work contributes to the DLR (German Aerospace Centre) project Particles 
and Cirrus Clouds (PAZI-2). The third author is supported by Airbus and the UK Department of Trade and Industry.

\section{References}

Bony S, Emanuel KA. 2001. A parameterization of the cloudiness associated with cumulus convection: Evaluation using TOGA COARE data. J. Atmos. Sci. 58: 3158-3183.

Gierens K. 2003. On the transition between heterogeneous and homogeneous freezing. Atmos. Chem. Phys. 3: 437-446.

Gierens K, Schumann U, Helten M, Smit H, Marenco A. 1999. A distribution law for relative humidity in the upper troposphere and lower stratosphere derived from three years of MOZAIC measurements. Ann. Geophysicae 17: 1218-1226.

Gierens K, Schumann U, Helten M, Smit H, Wang PH. 2000. Icesupersaturated regions and subvisible cirrus in the northern midlatitude upper troposphere. J. Geophys. Res. 105: 22743-22753.

Gierens K, Kohlhepp R, Spichtinger P, Schrödter-Homscheidt M. 2004. Ice supersaturation as seen from TOVS. Atmos. Chem. Phys. 4: 539-547.

Heymsfield AJ, Miloshevich LM, Twohy C, Sachse G, Oltmans S. 1998. Upper-tropospheric relative humidity observations and implications for cirrus ice nucleation. Geophys. Res. Lett. 25 : 1343-1346.

Huffman GJ, Adler RF, Arkin P, Chang A, Ferraro R, Gruber A, Janowiak J, McNab A, Rudolf B, Schneider U. 1997. The Global Precipitation Climatology Project (GPCP) combined precipitation dataset. Bull. Am. Meteorol. Soc. 78: 5-20.

IPCC. 1999. Aviation and the Global Atmosphere - A special report of IPCC Working Groups I and III, Penner JE, Lister DH, Griggs DJ, Docken DJ, McFarland M (eds). http://www.grida.no/climate/ ipcc/aviation/index.htm.

Jakob C. 2000. 'The representation of cloud cover in atmospheric general circulation models'. $\mathrm{PhD}$ thesis, University of Munich, Germany. Available from ECMWF, Shinfield Park, Reading RG2 9AX, UK.

Jensen EJ, Toon OB, Kinne S, Sachse GW, Anderson BE, Chan KR, Twohy CH, Gandrud B, Heymsfield AJ, Miake-Lye RC. 1998. Environmental conditions required for contrail formation and persistence. J. Geophys. Res. 103: 3929-3936.

John VO, Buehler SA. 2005. Comparison of microwave satellite humidity data and radiosonde profiles: A survey of European stations. Atmos. Chem. Phys. 5: 1843-1853.

Jung T, Tompkins AM, Rodwell MJ. 2005. Some aspects of systematic error in the ECMWF model. Atmos. Sci. Lett. 6: 133-139.

Kärcher B, Lohmann U. 2002. A parameterization of cirrus cloud formation: Homogeneous freezing of supercooled aerosols. J. Geophys. Res. 107: doi: 10.1029/2001JD000470.

Khvorostyanov V, Sassen K. 1998. Cirrus cloud simulation using explicit microphysics and radiation. Part II: Microphysics, vapor and ice mass budgets, and optical and radiative properties. J. Atmos. Sci. 55: $1822-1845$.

Koop T, Luo BP, Tsias A, Peter T. 2000. Water activity as the determinant for homogeneous ice nucleation in aqueous solutions. Nature 406: 611-614.

Li J-L, Waliser DE, Jiang JH, Wu DL, Read W, Waters JW, Tompkins AM, Donner LJ, Chern JD, Tao WK, Atlas R, Gu Y, Liou KN, Del Genio A, Khairoutdinov M, Gettelman A. 2005. Comparisons of EOS MLS cloud ice measurements with ECMWF analyses and GCM simulations: Initial results. Geophys. Res. Lett. 32: (L18), doi: 10.1029/2005GL023788.

Lin R-F, Starr D, DeMott PJ, Cotton R, Sassen K, Jensen E, Kärcher B, Liu X. 2002. Cirrus parcel model comparison project. Phase 1: The critical components to simulate cirrus initiation explicitly. J. Atmos. Sci. 59: 2305-2329.

Lohmann U, Kärcher B. 2002. First interactive simulations of cirrus cloud formed by homogeneous freezing in the ECHAM general circulation model. J. Geophys. Res. 107: (D10), doi: 10.1029/2001JD000767.

Lohmann U, Roeckner E. 1996. Design and performance of a new cloud microphysics scheme developed for the ECHAM general circulation model. Clim. Dyn. 12: 557-572.

Miloshevich LM, Vömel H, Whiteman DN, Lesht BM, Schmidlin FJ, Russo F. 2006. Absolute accuracy of water vapor measurements from six operational radiosonde types launched during AWEX-G, and implications for AIRS validation. J. Geophys. Res. 111: (D09), doi: 10.1029/2005JD006083.

Ovarlez J, van Velthoven P. 1997. Comparison of water vapor measurements with data retrieved from ECMWF analyses during the POLINAT experiment. J. Appl. Meteorol. 36: 1329-1335.

Ovarlez J, van Velthoven P, Sachse G, Vay S, Schlager H, Ovarlez H. 2000. Comparison of water vapor measurements from POLINAT 2 with ECMWF analyses in high-humidity conditions. J. Geophys. Res. 105: $3737-3744$.

Pruppacher HR, Klett JD. 1997. The Microphysics of Clouds and Precipitation. Kluwer Academic Publishers: Dordrecht, The Netherlands.

Rädel G, Stubenrauch CJ, Holz R, Mitchell DL. 2003. Retrieval of effective ice crystal size in the infrared: Sensitivity study and global measurements from TIROS-N Operational Vertical Sounder. J. Geophys. Res. 108: (D9), doi: 10.1029/2002JD002801.

Read WG, Waters JW, Wu DL, Stone EM, Shippony Z, Smedley AC, Smallcomb CC, Oltmans S, Kley D, Smit HGJ, Mergenthaler JL, Karki MK. 2001. UARS Microwave Limb Sounder upper tropospheric humidity measurement: Method and validation. J. Geophys. Res. 106: (D23), doi: 10.1029/2000JD000122.

Ren C, Mackenzie AR. 2005. Cirrus parametrization and the role of ice nuclei. $Q$. J. R. Meteorol. Soc. 131: 1585-1605.

Rossow WB, Schiffer RA. 1991. ISCCP cloud data products. Bull. Am. Meteorol. Soc. 72: 2-20.

Rossow WB, Schiffer RA. 1999. Advances in understanding clouds from ISCCP. Bull. Am. Meteorol. Soc. 80: 2261-2287.

Schumann U. 1996. On conditions for contrail formation from aircraft exhausts. Meteorol. Zeitschrift 5: 4-25.

Simmons AJ, Untch A, Jakob C, Kållberg P, Undén P. 1999. Stratospheric water vapour and tropical tropopause temperatures in ECMWF analyses and multi-year simulations. Q. J. R. Meteorol. Soc. 125: $353-386$.

Smith RNB. 1990. A scheme for predicting layer clouds and their water-content in a general-circulation model. Q. J. R. Meteorol. Soc. 116: $435-460$.

Soden BJ, Lanzante JR. 1996. An assessment of Satellite and radiosonde climatologies of upper-tropospheric water vapor. J. Climate 9: 1235-1250.

Soden BJ, Turner DD, Lesht BM, Miloshevich LM. 2004. An analysis of satellite, radiosonde, and lidar observations of upper tropospheric water vapor from the Atmospheric Radiation Measurement Program. J. Geophys. Res. 109: (D04), doi: 10.1029/2003JD003828.

Spice A, Johnson DW, Brown PRA, Darlison AG, Saunders CPR. 1999. Primary ice nucleation in orographic cirrus clouds: A numerical simulation of the microphysics. Q. J. R. Meteorol. Soc. 125: $1637-1667$.

Spichtinger P, Gierens K, Read W. 2003. The global distribution of ice-supersaturated regions as seen by the Microwave Limb Sounder. Q. J. R. Meteorol. Soc. 129: 3391-3410.

Stephenson DB. 2000. Use of the 'odds ratio' for diagnosing forecast skill. Weather and Forecasting 15: 221-232.

Tiedtke M. 1993. Representation of clouds in large-scale models. Mon. Weather Rev. 121: 3040-3061.

Tompkins AM. 2002. A prognostic parameterization for the subgridscale variability of water vapor and clouds in large-scale models and its use to diagnose cloud cover. J. Atmos. Sci. 59: 1917-1942.

Tompkins AM, Bechtold P, Beljaars A, Benedetti A, Cheinet S, Janisková M, Köhler M, Lopez P, Morcrette J-J. 2004. 'Moist physical processes in the IFS: Progress and plans'. Technical Memorandum 452, ECMWF, Reading, UK. http://www.ecmwf.int/ publications/.

Wang JH, Cole HL, Carlson DJ, Miller ER, Beierle K, Paukkunen A, Laine TK. 2002. Corrections of humidity measurement errors from the Vaisala RS80 radiosonde - Application to TOGA COARE data. J. Atmos. Oceanic Technol. 19: 981-1002.

Wielicki BA, Barkstrom BR, Harrison EF, Lee RB, Smith GL, Cooper JE. 1996. Clouds and the earth's radiant energy system (CERES): An earth observing system experiment. Bull. Am. Meteorol. Soc. 77: 853-868.

Wilson D, Forbes R. 2004. 'The large-scale precipitation parametrization scheme'. Unified Model Documentation Paper 26. Met Office, Fitzroy Road, Exeter EX1 3PB, UK. 